\title{
Robotic assisted lobectomy for locally advanced lung cancer
}

\author{
Giulia Veronesi ${ }^{1}$, Pierluigi Novellis ${ }^{1}$, Orazio Difrancesco ${ }^{2}$, Mark Dylewski $^{3}$ \\ ${ }^{1}$ Division of Thoracic Surgery, ${ }^{2}$ Department of Anesthesia and Intensive Care Unit, Humanitas Clinical and Research Center, Rozzano, Milan, Italy; \\ ${ }^{3}$ Thoracic and Robotic Surgery, Baptist Health of South Florida, Miami, Florida, USA \\ Contributions: (I) Conception and design: G Veronesi; (II) Administrative support: None; (III) Provision of study materials or patients: M Dylewski, O \\ Difrancesco; (IV) Collection and assembly of data: P Novellis; (V) Data analysis and interpretation: None; (VI) Manuscript writing: All authors; (VII) \\ Final approval of manuscript: All authors. \\ Correspondence to: Pierluigi Novellis. Thoracic Surgery Division, Humanitas Clinical and Research Center, Via Manzoni 56, 20089, Rozzano, Milano, \\ Italy. Email: pierluigi.novellis@cancercenter.humanitas.it.
}

\begin{abstract}
Some series report the use of video-assisted thoracic surgery (VATS) in patients with locally advanced non-small cell lung cancer (NSCLC) but, few studies describe the use of the robotic approach specifically for locally advanced disease. One potential advantage of the robotic approach over traditional VATS is the increased radicality. While the benefit of the robotic approach over open thoracotomy is directly related to reduced surgical trauma and the improved tolerability in fragile patients that have received induction treatment. In case of occult N2 disease, robotic assisted surgery can translate into a quicker recovery with improved compliance with adjuvant treatments following surgery. Technical details are reported and described. The robotic instrument technology allows sharp and controlled dissection compared to the typical blunt sweeping methods used in most VATS lobectomy techniques. The authors believe that robotic technology favors a more radical resection in the case of complex locally advanced tumors. Robotic technology has some limitations that have affected adoption such as significant capital and maintenance costs, reduced operating room efficiencies, and a steep learning curve.
\end{abstract}

Keywords: Lung cancer; locally advanced; robotic surgery; multimodality treatment

Received: 26 March 2017; Accepted: 11 April 2017; Published: 04 June 2017.

doi: 10.21037 /jovs.2017.04.03

View this article at: http://dx.doi.org/10.21037/jovs.2017.04.03

\section{Introduction}

Stage III non-small cell lung cancer (NSCLC) represents a heterogeneous group of patients (1) and the treatment of such patients may be a challenge because of their local presentation, requiring extended resection for infiltration of vital mediastinal organs or involvement of loco-regional mediastinal lymph nodes (N2), and the risk of metastatic recurrence (1).

Many advancements in multi-modality managements strategies have occurred in the last decade that has impacted patient operability and overall disease-free survival. Improvements in radiographic staging modalities may be a factor improving outcomes in patients treated with stage III NSCLC in recent studies compared with previous trials. In addition, there have been improvements made in surgery as well as adjuvant and neoadjuvant chemotherapy that clearly has impacted survival; thus, become a standard of care in operable stage III patients (2,3). Lastly, the radiotherapy has gone through revolution in technical advancements that allow for safer integration with chemotherapy and surgery (4). Given the complex nature of patients with stage III NSCLC and the challenging multi-modality approach that is necessary to achieve successful outcomes, treatment for patients with stage III disease should always be organized by a multidisciplinary team $(5,6)$.

Surgical resection remains an integral part of the multidisciplinary management strategy for selected stage IIIA (N2) patients (7). Despite improvements made in minimally invasive surgical techniques along with the introduction of lung sparing techniques, improved pre- and post-operative care, the use of minimal-invasive surgery still remains 
uncommon at many centers (8). The robotic approach using the da Vinci system (8-11) represents a technological evolution in the video-assisted surgical approach (12-15). The robotic platform lends itself to several technical advantages such as better view of the operative field (3D instead of 2D), intuitive use of the tools (instruments), precise movement of the instruments and to the many possibilities derived from flexibility and maneuverability of the instruments, which is even superior to that of the human hands $(16,17)$. These improvements can be translated into a greater chance of shortening and simplifying the time of some surgical steps, such as that of the radical lymphadenectomy, bronchial suturing, dissection of hylar lymph nodes from vascular structures. Fore-the-most-part, these advanced skills require years of training and practice when performed with the conventional video-thoracoscopic technique $(18,19)$.

Among the many advantages of minimally invasive surgical approaches over traditional thoracotomy, one is the surgical effect on the immune system (20-22). In particular, the surgical trauma causing an inflammatory condition characterized by the release of pro-inflammatory cytokines and acute phase proteins. Surgical manipulation also exerts a depressing cell-mediated immunity, which is manifested through the alteration in the cell, activation and function of lymphocytes and monocytes. The magnitude of these effects is proportional to the extent of the surgical procedure (21). One possible clinical consequence of the observed immunological changes can be the reported improved overall 4 years survival of patients treated with video-assisted thoracic surgery (VATS) lobectomies compared to thoracotomies (23).

The commonly accepted indications for minimally invasive approach in lung cancers with VATS are localized stage I or II disease (24). Some series report the use of VATS in patients with locally advanced NSCLC $(16-19,25,26)$, but few studies describe the use of the robotic approach specifically for locally advanced disease (27). One potential advantage of the robotic approach over traditional VATS is the increased radicality. While the benefit of the robotic approach over open thoracotomy is directly related to reduced surgical trauma and the improved tolerability in fragile patients that have received induction treatment. In case of occult N2 disease, robotic assisted surgery can translate into a quicker recovery with improved compliance with adjuvant treatments following surgery. In addition, a potential oncological benefit can be obtained with the reduced immune system activation.

The aim of this study is to describe the robotic surgical technique for surgical management of locally advanced lung cancer both before or after induction treatment.

\section{Patient selection and workup}

Staging procedure in patients with locally advanced NSCLC included CT with contrast of the brain, chest, and abdomen, total body ${ }^{18}$ FDG PET-CT. In cases of suspicious $\mathrm{N} 2$ disease at imaging endobronchial ultrasound (EBUS) or mediastinoscopy confirmation was usually performed of paratracheal and subcarinal lymph node stations. Patients with a preoperative diagnosis of single station or resectable $\mathrm{N} 2$ disease were candidate for preoperative induction treatment with CDDP based chemotherapy for three cycles. The post-treatment staging exams including CT/PET and CT of the brain with contrast. In cases where the disease was deemed resectable, patient was considered a candidate for the robotic surgical approach within 30-45 days from the last chemotherapy. Major contraindications to robotic approach were the intrapericardial pneumonectomy, major vascular resection and reconstruction, atrial resections, extended chest wall resections and masses with the minimum diameter larger than $8-10 \mathrm{~cm}$ requiring rib spreading to remove the mass itself.

\section{Preoperative preparation}

Preoperative anesthetic evaluation does not differ much from routine evaluation for thoracic surgery. Locally advanced tumors are more prone to involve big vessels or mediastinal structures, therefore preoperative discussion between anesthesiologist and surgeon is mandatory to recognize in advance possible intraoperative problems (bleeding problems, difficult airways managing etc.).

Standard preoperative tests is utilized including: chest $\mathrm{X}$-ray, ECG, blood tests and pulmonary function test (PFT). The use of additional testing for cardiopulmonary evaluation was used on a selective basis.

\section{Anesthesia management}

The patient is administer short-acting benzodiazepines (midazolam) following the anesthesiologists assessment and then brought to the operating room. Standard general anesthesia is administered and the airway is secured with and double lumen Carlens endotracheal tube. Careful attention is paid to limiting the total IV fluids to less than $1,000 \mathrm{~mL}$, oxygen level is kept at the lowest level that 


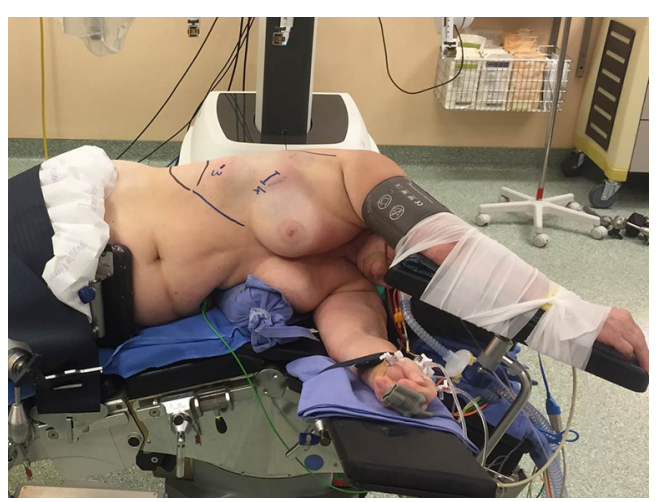

Figure 1 Patient position.

allows the patient to maintain saturations in the mid $90 \%$ level, and ventilation pressures are stricting observed to avoid barotrauma in the contralateral lung tissue. After positioning and checking double lumen tube, we cannulate two large caliber peripheral veins and place a radial artery monitoring line in the arm contralateral to the operative side. Central intravenous lines are used selectively. If any involvement of central mediastinal vessels is expected, we position a 8.5 -french catheter in the femoral vein. Then, we position patient on operatory bed as requested (normally, it's an intermediate lateral decubitus with homolateral arm kept down to easy robot arms working), after we start one lung ventilation and we administer intercostal nerve blocking with L-bupivacaine $0.5 \% 3 \mathrm{~mL} /$ space from $\mathrm{T} 3$ to T8. Intraoperative opioids are used, preferring short-acting drugs as remifentanil. Muscle blockade is obtained with rocuronium. Bladder line is positioned.

At the end of surgery, we extubate patients in operating room (OR), then we transfer them in recovery room where we keep them 90-120 min controlling chest X-ray, blood gas analysis, pain, diuresis and adequate drainage tube (blood or air leaking). Pain control after surgery is warranted by opioids and nonsteroidal anti-inflammatory drugs (NSAIDs) [normally we administer for the first 24-hour morphine 20 $\mathrm{mg}$ /day and Ketorolac or ketoprofene, paying attentions to postoperative nausea and vomiting (PONV) therapy and gastric protection]. Patients are then transferred to surgery ward.

\section{Equipment preference card}

After the intubation, the patient is positioned in lateral decubitus and the dependant portions of the body and arms are padded appropriately (Figure 1). The operating table is flexed at the level of the kidney rest. Alternatively, a pillow or a 3-L insufflation bag can be placed under the hip to achieve the same positioning. A four-arm robotic approach is used with Xi or Si Da Vinci system. A utility incision of $3-\mathrm{cm}$ is performed in the $4^{\text {th }}$ intercostal space anteriorly and a skin retractor is placed (Alexis). Under direct vision the 8 -mm camera port is introduced in the (the Blue is confusing) $8^{\text {th }}$ intercostal space in the anterior axillary line, two other ports are introduced when possible, along the same intercostal space as the camera port respectively on the line of the tip of the scapula and in the auscultatory triangle (Figure 2). Dylewski et al. and Cerfolio et al. have described alternative techniques for performing the complete portal robotic lobectomy (CPRL) with the use of either three or four robotic port. The technique is a closed chest approach using continuous $\mathrm{CO}_{2}$ insufflation, with the removal of the specimen performed at the end of the case via a subcostal para-diaphragmatic approach $(16,17)$.

\section{Procedure}

\section{Mediastinal exploration and lymph node dissection}

The operation begins with a hilar release and radical dissection of lymph node stations.

The preoperative PET/CT provides guidance for nodal station assessment to determine resectability.

The pulmonary ligament is dissected and station R9 lymph nodes are removed, dissection is continued till the inferior pulmonary vein is identified. Explore of the subcarinal station from the right side, the lung is retracted anteriorly using the tip up instrument introduced in the posterior arm (the $4^{\text {th }}$ ). The posterior pleura from the upper part of the inferior vein to the azygos vein along the intermediate bronchus is opened (Figure 3). The lymph nodes are removed en bloc by dissecting the oesophagus off the sub-carinal area, exposing the right and left main bronchi. Following the bronchus intermedius proximal from the right side the node is freed from the bronchus and dissected off the posterior pericardium is recognised. Care must be taken not to tear the lymph node capsule in order to reduce bothersome bleeding that will slow the pace of the surgery. The bronchial arteries are usually clipped or coagulated using bipolar energy (curved bipolar dissector with the energy source set at 8) (Figure 4).

After removal of the nodal specimen, by the bedside assistant through the utility incision, an hemostatic sponge is left in the sub-carinal space. 

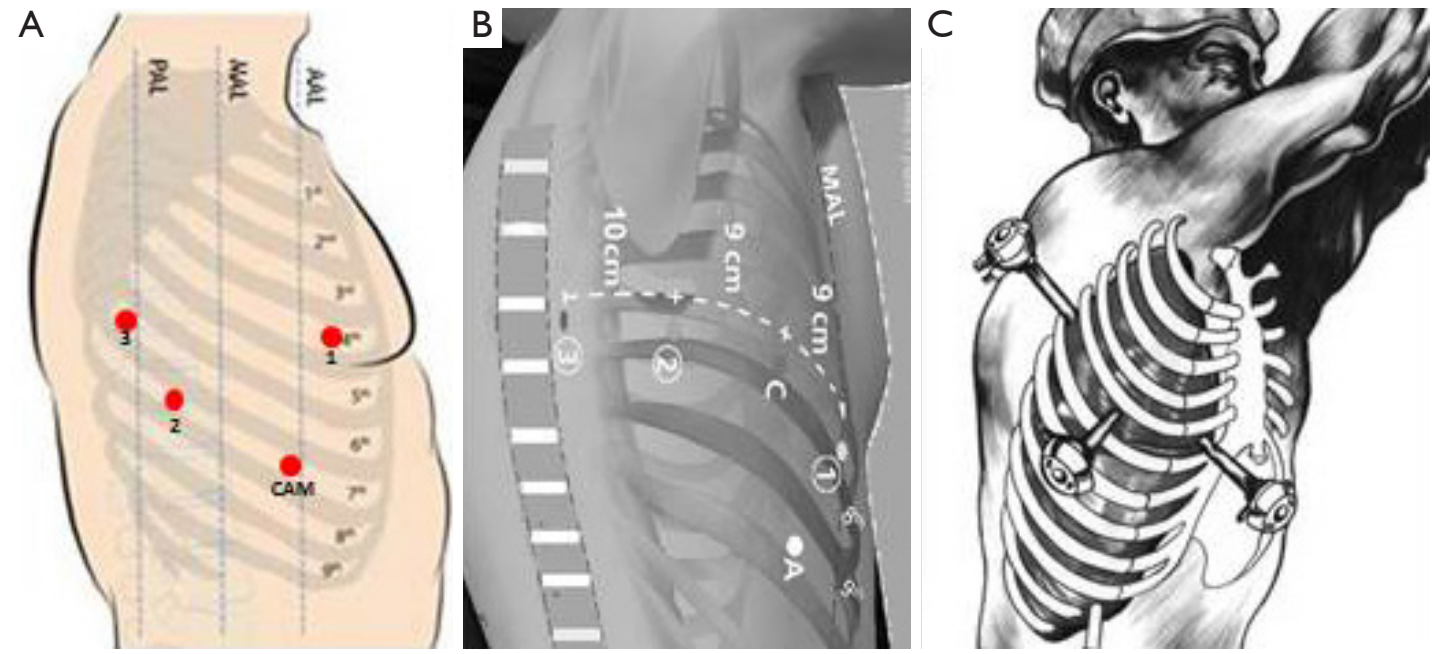

Figure 2 Robotic ports and utility incision.

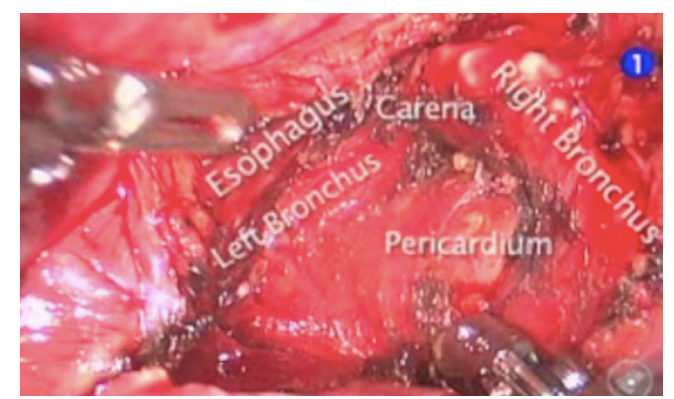

Figure 3 Lymph node dissection of station $7^{\text {th }}$ from the right side.

The lymph node dissection at the level of the paratracheal stations, R2 and R4, and level 3 begins with obtaining exposure by using the tip-up grasper through the $4^{\text {th }}$ arm port to retract the upper lobe inferiorly. The truncus anterior vessel is dissected and the R4 lymph node on the anterior of the vessel is removed. The dissection can be continued underneath the azygous vein to begin removing level 3 nodes. The last step is to dissect above the azygous and between the superior vena cava (SVC) and the anterior margin of the trachea to remove R2 and all level 3 nodes together. In the face of locally advanced disease, large nodes and previous radiation, the authors advise dividing the azygous to assist with exposure (Figure 5).

The dissection of the sub-carinal station from the left side is more difficult due to the presence of the descending aorta. In an effort to improve exposure of the sub-carinal space, the use of $\mathrm{CO}_{2}$ in a closed chest port-only approach

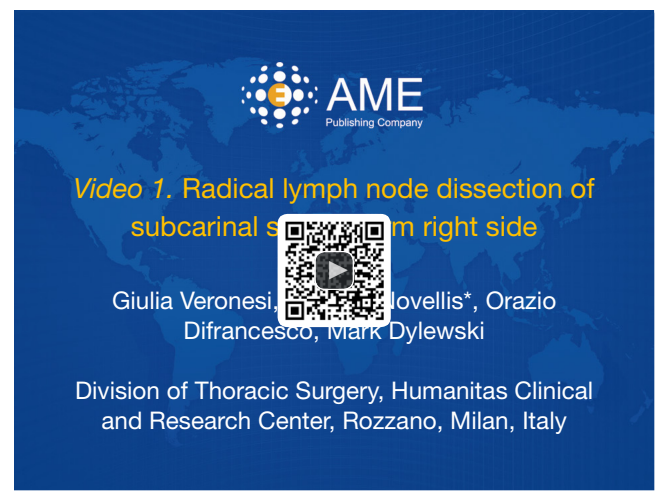

Figure 4 Radical lymph node dissection of subcarinal station form right side (28).

Available online: http://www.asvide.com/articles/1543

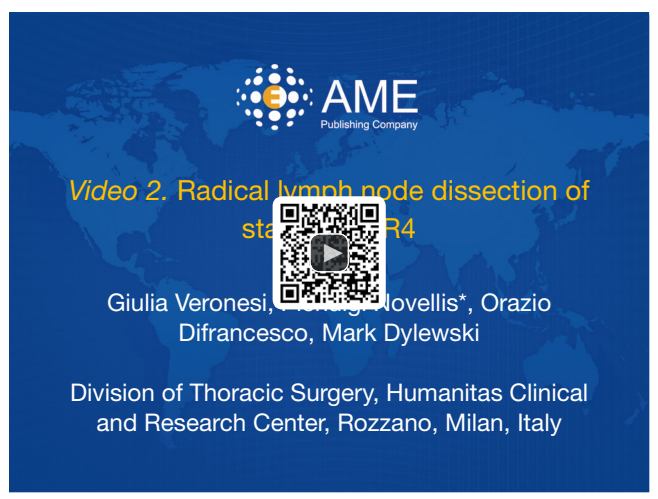

Figure 5 Radical lymph node dissection of station R2-R4 (29). Available online: http://www.asvide.com/articles/1544 


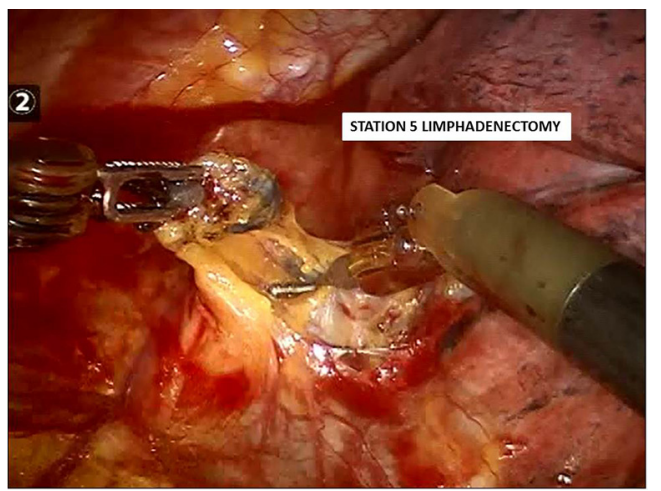

Figure 6 Station $5^{\text {th }}$ and station $6^{\text {th }}$ lymph nodes dissection (left side).

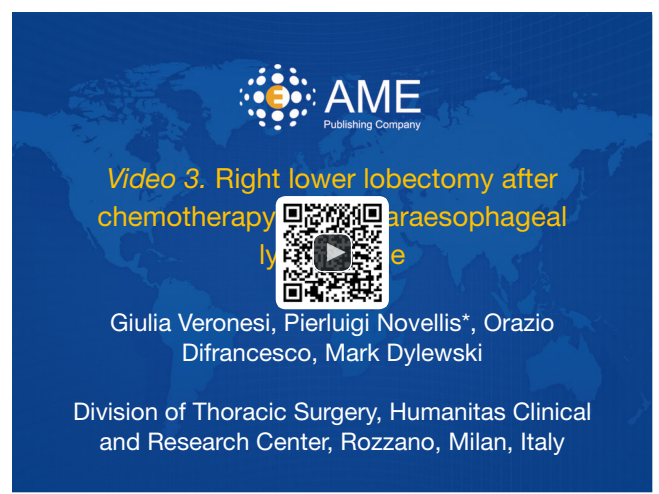

Figure 7 Right lower lobectomy after chemotherapy for N2 paraesophageal lymph node (30).

Available online: http://www.asvide.com/articles/1545

will help. In addition, retraction upward on the left lower lobe bronchus improves exposure especially after dividing the inferior pulmonary vein in a lower lobectomy.

While releasing the tissue along the posterior hilum, the main left pulmonary artery should be exposed and dissection carried distally under the posterior margin of the lung tissue in order to identify the superior segmental and ascending posterior arterial branches. During this process, and the dissection over the suprahilar area, level 5 and level 6 lymph nodes should be removed (Figure 6). When removing lymph nodes in the aorto-pulmonary window one should pay attention to sparing the recurrent laryngeal nerve as it traverses under the aortic arch and the phrenic nerve anterior to the superior pulmonary vein. On the right side, the recurrent laryngeal nerve can inadvertently be injured during the supra-hilar lymph node dissection if one carries the dissection too superiorly along the trachea. The phrenic nerve lies anterior to the right superior pulmonary vein similar to the left side phrenic nerve.

\section{Lung resection}

\section{Right side}

The lobectomy is performed with an anterior to posterior approach to the hilum [robotic-assisted thoracic surgery (RATS) technique described by Park and Veronesi] $(8,9)$ or posterior to anterior approach (CPRT by Dylewski and Cerfolio) (16,17).

The sequence for right upper lobectomy for the RATS technique is vein, arteries (two branches), bronchus and fissure. The traditional endoscopic stapler for vessel transection is introduced through the posterior port after removal of the robotic arm, to avoid a $5^{\text {th }}$ trocar. To complete the fissure staplers are introduced through the anterior utility incision. If the hospital is equipped with robotic staplers the site of introduction is chosen by the surgeon in a more flexible way.

For (RATS) lower lobectomy, the sequence is vein, arteries, posterior fissure and bronchus. Staplers are introduced through the superior anterior utility incision (the same of the right hand robotic arm). The middle lobe sequence is vein, fissure with lower lobe, bronchus and arteries and fissure.

\section{Left side}

The (RATS) left upper lobe, the lung is retracted posteriorly by the fourth arm to explore the hilum, the staplers for vessels are introduced through the posterior port after removal of the robotic arm. The sequence of the (RATS) left lower lobectomy is similar to the right lower except the absence of middle lobe bronchus.

\section{Specimen removal}

The specimen is usually removed using a plastic bag through the utility incision in the RATS technique or through the para-diaphragmatic incision in case of the CPRL technique.

\section{Right lower lobectomy (Figure 7) (double speed)}

The movie shows a right lower lobectomy after chemotherapy for $\mathrm{N} 2$ paraesophageal lymph node in a 63-year-old former male smoker. The patient was diagnosed with a right lower adenocarcinoma T1N2 single paraesophageal station, confirmed with endoscopic ultrasound (EUS) needle biopsy and a synchronous left 


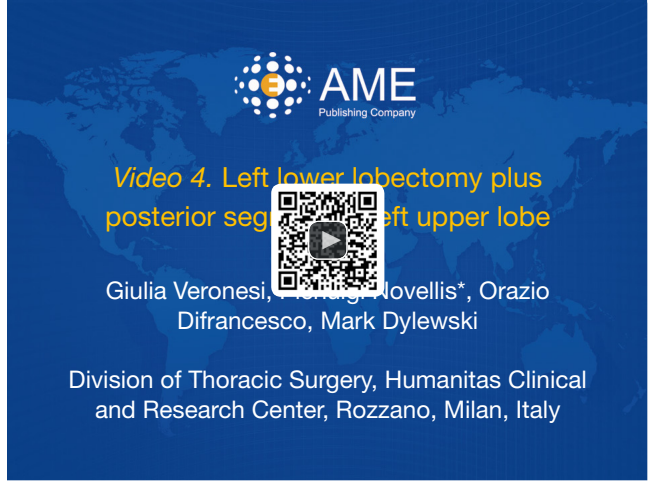

Figure 8 Left lower lobectomy plus posterior segment of left upper lobe (31).

Available online: http://www.asvide.com/articles/1546

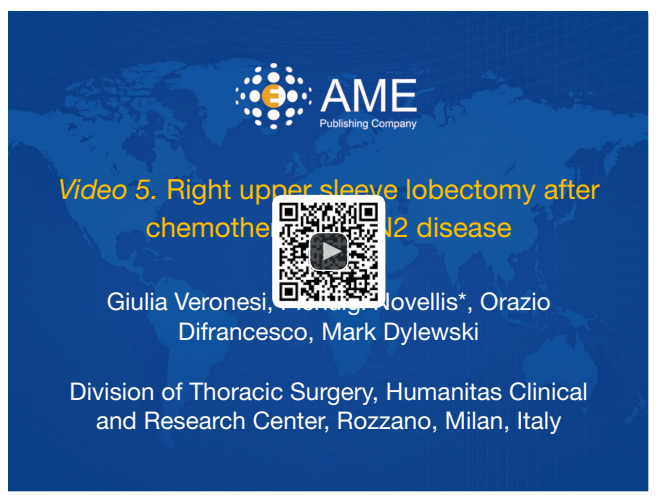

Figure 9 Right upper sleeve lobectomy after chemotherapy for N2 disease (32).

Available online: http://www.asvide.com/articles/1547

lower lobe adenocarcinoma stage clinical T1N0M0. After chemotherapy with partial response of the right lower lobe malignancy, he underwent sequential surgeries that including initially a right lower lobectomy with lymph node dissection followed by a robotic left superior segmentectomy. The postoperative course for this patient was uneventful and he is free of disease after 3 years.

\section{Left lower lobectomy plus posterior segment of left upper lobe (Figure 8)}

A 60-year-old smoker was diagnosed with left lower lung lesions with infiltration across the fissure of the posterior segment of the upper lobe with a clinical T3N1M0 stage. He received preoperative induction platinum based chemotherapy and subsequently a robotic left lower lobectomy en bloc with posterior segment of the upper lobe and radical lymph node dissection was performed. The challenges of this case were that the lymph nodes within the central hilum were adherent to the artery and difficult to be removed. After completion of posterior fissure and carefully removing the attached lymph nodes, A branch for the posterior segment was isolated and resected between hemo-locks. The parenchima resection was performed including the portion of the left upper lobe involved by the tumor, en bloc with the lower lobe. After these steps the case proceeded routinely.

\section{Right upper sleeve lobectomy after chemotherapy for N2 disease (Figure 9)}

The patient is a 71-year-old male smoker who presented with a T3N2M0 right upper lobe tumor with large suprahilar lymph nodes significantly covering the anterior truncus artery. Difficult was encountered achieving exposure and isolation of the origin of the truncus anterior vessel and the right upper lobe bronchus. For that reason, the azygous vein was divided anteriorly and posteriorly to the supra-hilar tumor. After removing the freeing the large level R2 and level 3 nodes from the supra-hilar space, they could not be removed to unroof the truncus anterior artery. Therefore, access to the origin of the truncus anterior was achieved by dividing the right upper lobe bronchus off its origin with endoscissors, Once the right upper lobe bronchus was transected, the origin of the artery was exposed by removing the R10 lymph node anterior to the bronchus. Once the truncus anterior artery is divided, the operation proceeded normally. A right upper lobe bronchoplastic closure of the open upper lobe bronchus was preformed along with a pleural flap.

\section{Post-operative management}

At the completion of the procedure: patients are typically extubated in OR and remain in the post-anesthesia care unit (PACU) for 2-4 hours. A chest X-ray, amount of drained liquid, and vital signs are monitored checking. When stable, they are sent to a monitored bed in the surgical ward.

Postoperative pain therapy: elastomer $(50 \mathrm{~mL}$ volume, $2 \mathrm{~mL} / \mathrm{h}$ ) with morphine $0.4 \mathrm{mg} / \mathrm{kg}$, ketorolac $1.2 \mathrm{mg} / \mathrm{kg}$, ranitidine $150 \mathrm{mg}$ and ondansetron $8 \mathrm{mg}$. An Acute Pain Service is active in our institution with a double-daily check of patients' pain.

Patients are soon mobilized, 6- 8 hours after surgery, if 
vital parameters are adequate. Twelve hours after surgery they are allowed to eat. Pulmonary rehabilitation starts on post-op day \#1. Chest tube drain is removed when the quantity of liquid is lower than $350 \mathrm{~mL} / 24 \mathrm{~h}$ and no air leaks are visible.

\section{Tips, tricks and pitfalls}

- During lobectomies performed on patients at clinical stage IIIA, where a chemotherapy has already been administered, tissues are usually more fragile than in patients with occult N2 or at the initial stage. In this case, it is important to pay more attention in vascular dissection in order to avoid bleeding.

* The resection of the Barety lodge has to be very accurate in N2 patients. As well as in open surgery, in robotics it is possible to clamp and split the azygos vein, to better expose the lodge and ensure an extended lymphadenectomy.

* In the case in which there is a high diaphragm a stich can be used to stretch the diaphragm down fixing it to the chest wall at level of 10 intercostal space or lower, to expose better the hilum and the mediastinum.

* We recommend to place always in the resected lymph nodes lodge an hemostatic material to compress and fill the empty space to prevent the bleeding and lymphatic leakage.

\section{Conclusions}

Stage III NSCLC represent a heterogenous group of patients with pulmonary malignancies. Factors such as large central tumors, multi-station lymph node involvement, T3/T4 involvement, desmoplastic fibrosis and previous irradiate surgical fields make the surgical management of these patients challenging and the outcomes are often variable. Surgery continues to play a central role a select group of stage III NSCLC patients who disease is associated with good prognostic factors. These prognostic factors that predict improved outcomes for surgery patients included limited station mediastinal lymph node disease, response to induction therapy, no comorbidity (33). When patients with stage III NSCLC are found to have good prognostic factors and are consider candidates for surgical resection, a minimally invasive surgical approach has shown to offer favourable outcomes (34). Petersen et al. demonstrated reduced complications, length of stay, lower blood loss and decreased mortality. Other authors have shown a positive effect on the immune system correlated to a minimally invasive surgery (MIS) approach (20-22). Robotic approach in this contest can extend the indication of minimally invasive approach in patients with more advanced disease. There have been tremendous advancements made in robotic technology and the platform has certain advantages when surgically treating locally advanced NSCLC. These advantages include, improved mediastinal lymph node dissection, precise control of instruments for dissection for invasive tumours attached to critical structures. The robotic instrument technology allows sharp and controlled dissection compared to the typical blunt sweeping methods used in most VATS lobectomy techniques. The authors believe that robotic technology favors a more radical resection in the case of complex locally advanced tumours. Robotic technology has some limitations that have affected adoption such as significant capital and maintenance costs $(35,36)$, reduced operating room efficiencies, and a steep learning curve (37). For these reasons, the integration of the robotic platform into the management of complex locally advanced disease should be measured and only implemented after proven success on an adequate number of standard lobectomies before approaching more complex situation such as lobectomy after chemotherapy or lobectomy for N2 disease (38).

\section{Acknowledgements}

Authors thank the Umberto Veronesi Foundation for fellowships to Pierluigi Novellis.

\section{Footnote}

Conflicts of Interest: G Veronesi is a consultant for ABI Medica SpA and Medtronic. M Dylewski is a clinical educator for Intuitive Surgical and he has received honoraria by Verb Medical, Ethicon and Barb Corp. The other authors have no conflicts of interest to declare.

\section{References}

1. Goldstraw P, Crowley J, Chansky K, et al. The IASLC Lung Cancer Staging Project: proposals for the revision of the TNM stage groupings in the forthcoming (seventh) edition of the TNM Classification of malignant tumours. J Thorac Oncol 2007;2:706-14.

2. Pignon JP, Tribodet H, Scagliotti GV, et al. Lung adjuvant cisplatin evaluation: a pooled analysis by the LACE 
Collaborative Group. J Clin Oncol 2008;26:3552-9.

3. NSCLC Meta-analyses Collaborative Group, Arriagada R, Auperin A, et al. Adjuvant chemotherapy, with or without postoperative radiotherapy, in operable non-small-cell lung cancer: two meta-analyses of individual patient data. Lancet 2010;375:1267-77.

4. De Ruysscher D, Faivre-Finn C, Nestle U, et al. European Organisation for Research and Treatment of Cancer recommendations for planning and delivery of high-dose, high-precision radiotherapy for lung cancer. J Clin Oncol 2010;28:5301-10.

5. Eberhardt WE, De Ruysscher D, Weder W, et al. 2nd ESMO Consensus Conference in Lung Cancer: locally advanced stage III non-small-cell lung cancer. Ann Oncol 2015;26:1573-88.

6. Decaluwé H, De Leyn P, Vansteenkiste J, et al. Surgical multimodality treatment for baseline resectable stage IIIA-N2 non-small cell lung cancer. Degree of mediastinal lymph node involvement and impact on survival. Eur J Cardiothorac Surg 2009;36:433-9.

7. Robinson LA, Ruckdeschel JC, Wagner H Jr, et al. Treatment of non-small cell lung cancer-stage IIIA: ACCP evidence-based clinical practice guidelines ( 2 nd edition). Chest 2007;132:243S-265S.

8. Park BJ, Flores RM, Rusch VW. Robotic assistance for video-assisted thoracic surgical lobectomy: technique and initial results. J Thorac Cardiovasc Surg 2006;131:54-9.

9. Veronesi G, Galetta D, Maisonneuve P, et al. Four-arm robotic lobectomy for the treatment of early-stage lung cancer. J Thorac Cardiovasc Surg 2010;140:19-25.

10. Zhao X, Qian L, Lin H, et al. Robot-assisted lobectomy for non-small cell lung cancer in china: initial experience and techniques. J Thorac Dis 2010;2:26-8.

11. Melfi FM, Mussi A. Robotically assisted lobectomy: learning curve and complications. Thorac Surg Clin 2008;18:289-95, vi-vii.

12. Demmy TL, Curtis JJ. Minimally invasive lobectomy directed toward frail and high-risk patients: a case-control study. Ann Thorac Surg 1999;68:194-200.

13. Hoksch B, Ablassmaier B, Walter M, et al. Complication rate after thoracoscopic and conventional lobectomy. Zentralbl Chir 2003;128:106-10.

14. Nakata M, Saeki H, Yokoyama N, et al. Pulmonary function after lobectomy: video-assisted thoracic surgery versus thoracotomy. Ann Thorac Surg 2000;70:938-41.

15. McKenna RJ Jr, Wolf RK, Brenner M, et al. Is lobectomy by video-assisted thoracic surgery an adequate cancer operation? Ann Thorac Surg 1998;66:1903-8.
16. Dylewski MR, Ohaeto AC, Pereira JF. Pulmonary resection using a total endoscopic robotic video-assisted approach. Semin Thorac Cardiovasc Surg 2011;23:36-42.

17. Cerfolio RJ, Bryant AS, Skylizard L, et al. Initial consecutive experience of completely portal robotic pulmonary resection with 4 arms. J Thorac Cardiovasc Surg 2011;142:740-6.

18. Huang J, Xu X, Chen H, et al. Feasibility of complete video-assisted thoracoscopic surgery following neoadjuvant therapy for locally advanced non-small cell lung cancer. J Thorac Dis 2013;5 Suppl 3:S267-73.

19. Nakanishi R, Fujino Y, Yamashita T, et al. Thoracoscopic anatomic pulmonary resection for locally advanced nonsmall cell lung cancer. Ann Thorac Surg 2014;97:980-5.

20. Nomori H, Ohtsuka T, Horio H, et al. Difference in the impairment of vital capacity and 6-minute walking after a lobectomy performed by thoracoscopic surgery, an anterior limited thoracotomy, an anteroaxillary thoracotomy, and a posterolateral thoracotomy. Surg Today 2003;33:7-12.

21. Yim AP, Wan S, Lee TW, et al. VATS lobectomy reduces cytokine responses compared with conventional surgery. Ann Thorac Surg 2000;70:243-7.

22. Li WW, Lee RL, Lee TW, et al. The impact of thoracic surgical access on early shoulder function: video-assisted thoracic surgery versus posterolateral thoracotomy. Eur J Cardiothorac Surg 2003;23:390-6.

23. Whitson BA, Groth SS, Duval SJ, et al. Surgery for earlystage non-small cell lung cancer: a systematic review of the video-assisted thoracoscopic surgery versus thoracotomy approaches to lobectomy. Ann Thorac Surg 2008;86:200816; discussion 2016-8.

24. Yan TD, Cao C, D'Amico TA, et al. Video-assisted thoracoscopic surgery lobectomy at 20 years: a consensus statement. Eur J Cardiothorac Surg 2014;45:633-9.

25. Hennon M, Sahai RK, Yendamuri S, et al. Safety of thoracoscopic lobectomy in locally advanced lung cancer. Ann Surg Oncol 2011;18:3732-6.

26. Gonzalez-Rivas D, Fieira E1, Delgado M1, et al. Is uniportal thoracoscopic surgery a feasible approach for advanced stages of non-small cell lung cancer? J Thorac Dis 2014;6:641-8.

27. Park BJ, Yang HX, Woo KM, et al. Minimally invasive (robotic assisted thoracic surgery and video-assisted thoracic surgery) lobectomy for the treatment of locally advanced non-small cell lung cancer. J Thorac Dis 2016;8:S406-13.

28. Veronesi G, Novellis P, Difrancesco O, et al. Radical lymph node dissection of subcarinal station form right 
side. Asvide 2017;4:234. Available online: http://www. asvide.com/articles/1543

29. Veronesi G, Novellis P, Difrancesco O, et al. Radical lymph node dissection of station R2-R4. Asvide 2017;4:235. Available online: http://www.asvide.com/ articles $/ 1544$

30. Veronesi G, Novellis P, Difrancesco O, et al. Right lower lobectomy after chemotherapy for N2 paraesophageal lymph node. Asvide 2017;4:236. Available online: http:// www.asvide.com/articles/1545

31. Veronesi G, Novellis P, Difrancesco O, et al. Left lower lobectomy plus posterior segment of left upper lobe. Asvide 2017;4:237. Available online: http://www.asvide. com/articles/1546

32. Veronesi G, Novellis P, Difrancesco O, et al. Right upper sleeve lobectomy after chemotherapy for $\mathrm{N} 2$ disease. Asvide 2017;4:238. Available online: http://www.asvide. com/articles/1547

33. Yoon SM, Shaikh T, Hallman M. Therapeutic management options for stage III non-small cell lung cancer. World J Clin Oncol 2017;8:1-20.

doi: $10.21037 /$ jovs.2017.04.03

Cite this article as: Veronesi G, Novellis P, Difrancesco O, Dylewski M. Robotic assisted lobectomy for locally advanced lung cancer. J Vis Surg 2017;3:78.
34. Petersen RP, Pham D, Toloza EM, et al. Thoracoscopic lobectomy: a safe and effective strategy for patients receiving induction therapy for non-small cell lung cancer. Ann Thorac Surg 2006;82:214-8; discussion 219.

35. Swanson SJ, Miller DL, McKenna RJ Jr, et al. Comparing robot-assisted thoracic surgical lobectomy with conventional video-assisted thoracic surgical lobectomy and wedge resection: results from a multihospital database (Premier). J Thorac Cardiovasc Surg 2014;147:929-37.

36. Deen SA, Wilson JL, Wilshire CL, et al. Defining the cost of care for lobectomy and segmentectomy: a comparison of open, video-assisted thoracoscopic, and robotic approaches. Ann Thorac Surg 2014;97:1000-7.

37. Veronesi G, Agoglia BG, Melfi F, et al. Experience with robotic lobectomy for lung cancer. Innovations (Phila) 2011;6:355-60.

38. Nasir BS, Bryant AS, Minnich DJ, et al. Performing robotic lobectomy and segmentectomy: cost, profitability, and outcomes. Ann Thorac Surg 2014;98:203-8; discussion 208-9. 